\title{
Dialogismo e Reflexidade: uma análise da contribuição dos Centros e Programas de Estudos de Gestão Social NO BRASIL
}

\author{
Dialogism and Reflexivity: an analysis of the contribution of the \\ Centers and Programs of Study Social Management in Brazil
}

\begin{abstract}
Júnia Guerra
Mestre em Gestão Social, Educação e Desenvolvimento Local - UNA-BH. Doutoranda do Programa de Pós-Graduação em Administração da Pontifícia Universidade Católica de Minas Gerais - PUC-MG. Belo Horizonte, MG, Brasil. E-mail: juniafcg71@ gmail.com

Armindo dos Santos de Sousa Teodósio

Doutor em Administração de Empresas pela Escola de Administração de Empresas do Estado de São Paulo da Fundação Getúlio Vargas. Professor do Programa de Pós-Graduação em Administração da Pontifícia Universidade Católica de Minas Gerais. Belo Horizonte, MG, Brasil. E-mail: teodósio@pucminas.br
\end{abstract}

\section{Resumo}

Este artigo tem como objetivo central analisar as possibilidades dialógicas e reflexivas para o ensino e a pesquisa de Gestão Social no Brasil a partir da atuação de Centros e Programas de Estudo desse campo no país. Para tanto, foram discutidas temáticas que envolvem o construto teórico da Gestão Social e as suas implicações para o exercício do ensino e pesquisa acadêmicos por meio da perspectiva interdisciplinar. De cunho qualitativo, esta pesquisa investigou seis Centros e Programas de Estudo sobre Gestão Social no Brasil. Adotou a entrevista semiestruturada em profundidade com seus fundadores e coordenadores, bem como a pesquisa documental como instrumento de coleta de dados. Os resultados demonstraram que os Centros e Programas de Estudo investigados reconhecem a Gestão Social como gestão da coletividade social de um dado território, no qual são assumidas relações intersetoriais que, por sua vez, refletem em práticas dialógicas e reflexivas.

Palavras-chave: Dialogismo e Reflexidade. Gestão Social. Centros e Programas de Estudos.

\section{Abstract}

This article is aimed mainly at analyzing dialogic and reflexive possibilities for teaching and research in Social Management of Brazil from the operation of Centres and Study Programs of this field in the country. To do so, we discuss issues involving the theoretical construct of social management and its implications for the practice of teaching and academic research through interdisciplinary perspective. A qualitative study, this research investigated six Centers and Programs Study on Social Management in Brazil. Adopted a semi-structured in-depth interview with its founders and coordinators, as well as documentary research as instruments of data collection. The results showed that the Centers and Programs of Study investigated acknowledge the Social Management as managing social collectivity of a given territory in which it is assumed intersectoral relationships that, in turn, reflected in dialogical and reflective practices.

Keywords: Dialogism and Reflexivity. Social Management. Centres and Study Programs. 


\section{INTRODUÇÃO}

A Gestão Social pode ser apreendida como uma forma de compreensão das organizações e do gerenciamento que surge em um contexto marcado por uma "sociedade managerial", cujas características decorrem das ideias capitalistas como categorias dominantes do pensamento econômico e do mercado, atribuindo à empresa e as práticas de gestão um espaço central, de dominação e alienação da maioria (CHANLAT, 2000, p. 16; SACHS; LOPES; DOWBOR, 2010).

Esse fenômeno coloca em evidência as expressões: gestão, gerir e gestor vinculadas aos princípios administrativos da empresa privada, que elegeriam atributos como a eficácia, produtividade, performance, competência, empreendedorismo, qualidade total, cliente, produto e desempenho como prerrogativas de excelência organizacional (AKTOUF, 1996).

Entretanto, em face aos graves problemas afrontados pela sociedade, fragmentação do social, empobrecimento, precariedade, exclusão, risco ecológico, urge a necessidade de se ampliar os horizontes dos aspectos propriamente humanos. Assim, a dimensão social do desenvolvimento deixa de ser um "complemento", para se tornar um dos componentes essenciais da transformação social (CHANLAT, 2000).

No cenário apontado, seria possível observar o retorno do ator social ao se destacar que toda pessoa pode se constituir em um sujeito ativo e que a realidade das organizações se produz, reproduz e se transforma por meio da interação dos diferentes grupos e indivíduos que as compõem (DOWBOR, 1999).

A partir do reconhecimento desse sujeito coletivo, imbuído de subjetividade, crítica e

de reflexão de si mesmo, nasce a Gestão Social. Marcada pela ideia de centralidade do sujeito nas esferas sociais, suas dinâmicas tentam articular o pensamento técnico dos que trabalham com os processos econômicos com o pensamento imbuído de valores sociais. Essa perspectiva, ainda que assinalada por aspectos que buscam mediar as "[...] deformações das prioridades que levou aos dramas atuais [...]", (ARAÚJO, 2012, p. 15), sinaliza as dificuldades e os conflitos presentes em processos no qual se prevê a interação entre o social, o econômico e o político (ABRAMOVAY, 2012; DOWBOR, 2010).
Tal visão aproximaria a Gestão Social a valores e práticas fundados na democracia e cidadania, tendo em vista, o enfrentamento às expressões da questão social, da garantia dos direitos humanos universais e da afirmação dos interesses e espaços públicos como padrões de nova civilidade (DOWBOR, 2005). "Estes referenciais apontam a práxis da Gestão Social, como mediação para a cidadania, que se contrapõe à perspectiva instrumental e mercantil que vem sendo dada a este tema" (MAIA, 2005 p. 16).

Por se tratar de um tema recentemente explorado no cenário brasileiro e por estar associado às temáticas relativas às transformações do tecido social, o seu campo se encontra em construção ou "in progress" (BOULLOSA, 2009). Vários autores, como Tenório (1997), Fischer (1998), Junqueira (2000), Carrion (2001), Boullosa e Schommer (2005), França-Filho (2005), Pinho (2005) e Cançado (2011), revelam que o termo Gestão Social permeia um campo teórico em construção cuja indeterminação vem motivando, no contexto social e científico indagações acerca de seus fundamentos teóricos e práticos.

A crescente visibilidade e importância percebida nos últimos anos acerca da Gestão Social, tanto no meio acadêmico, quanto empresarial e governamental propiciou a oferta de estruturas de formação acadêmico-profissional cujos pressupostos didático-metodológicos, têm sido alvo de discussões. Tais discussões, impulsionadas por hipóteses construídas sobre a figura emergente da Gestão Social, elevam significativas reflexões e críticas sobre as propostas pedagógicas dos cursos em vigor no país com foco na formação do gestor social. Segundo Schommer $e$ Boullosa (2010), essas discussões, ainda, permeiam tentativas de instrumentalização dos cursos, os quais detêm processos de ensino e aprendizagem conduzidos hierarquicamente. Esse procedimento contraria o cerne da Gestão Social e contribui para delimitar precocemente um conceito ainda em construção. Todavia, há dinâmicas de ensino-aprendizagem que buscam consolidar os preceitos da Gestão Social por meio de práticas que se configuram em dialogicidade e em reflexidade.

Esse contexto induziu o presente artigo a analisar as possibilidades dialógicas e reflexivas para o ensino $e$ a pesquisa de Gestão Social no Brasil a partir da atuação de Centros e Programas de Estudo deste campo 
no país norteado pela seguinte pergunta de pesquisa: quais são as possibilidades dialógicas e reflexivas para o ensino e a pesquisa de Gestão Social no Brasil a partir da atuação dos Centros e Programas de Estudo deste campo? Para tanto, desenvolveu-se uma pesquisa qualitativa apoiada em entrevistadas semiestruturadas em profundidade e na análise de documentos provenientes das unidades de análise escolhidas. Foram investigados seis Centros e Programas de Estudo no Brasil os quais se apoiam nas temáticas que envolvem a Gestão Social.

Além dessa introdução, o artigo foi estruturado da seguinte forma. A primeira sessão discutiu as abordagens temáticas que norteiam a Gestão Social com o intuito de orientar a pesquisa realizada acerca da noção que os atores entrevistados têm sobre a Gestão Social como perspectiva para se desenvolver dinâmicas e articulações pautadas no diálogo e na reflexidade. A sessão seguinte apresentou os procedimentos metodológicos e as análises oriundas dos dados coletados. Por fim, nas considerações finais, foram discutidas as perspectivas que circundam a dialogicidade e a reflexidade nas práticas provenientes do ensino e pesquisa dos Centros e Programas de Estudo investigados, que demonstraram reconhecer a Gestão Social como gestão da coletividade social de um dado território, assumida por relações intersetoriais apoiadas em ações colaborativas. Essa perspectiva fomenta a dialogicidade e a reflexidade nas práticas de ensino e pesquisa sobre Gestão Social, gerando aprendizagem e produção de conhecimento mútua e recursiva.

\section{Gestão Social: campo em CONSTRUÇÃO, TEMÁTICAS EM EVIDÊNCIAS}

Derivada de um contexto marcado pela "sociedade managerial" cujas características decorrem das ideias capitalistas como categorias dominantes do pensamento econômico e do mercado (CHANLAT, 1999, p. 16), a Gestão Social destaca-se por suas características inovadoras ao se apoiar em valores e práticas oriundas dos desígnios democráticos e da cidadania os quais buscam a contraposição à perspectiva instrumental e mercantil (MAIA, 2005). Esses aspectos são mediados pela presença do sujeito coletivo, imbuído de subjetividade, crítica e reflexão de si mesmo.
A partir desse foco, nota-se a complexidade da realidade na qual a Gestão Social vem se inserindo, atribuindo-lhe perspectivas interdisciplinares, uma vez que, complexidade em latim, "Complexus significa aquilo que é tecido junto, entrelaçamentos múltiplos" (MARIOTTI, 2000). Essa proposição integra conhecimentos orientados para a solução de problemas que afetam pessoas, organizações e a realidade social na qual se inserem (MENDONÇA; GONÇALVES-DIAS; JUNQUEIRA, 2012).

Nesse sentido, observa-se que o campo da Gestão Social vem se constituindo por meio de múltiplos saberes, definições e práticas que precedem a lógica social, não se limitando a um conceito único. Todavia, vale destacar que, a popularização do termo a ela atrelada gera muita ambiguidade sobre o que está falando e tratando, podendo incorrer à prática da gestão dos problemas sociais ou ambientais e não a forma articulada de organizar o conjunto para que funcione (PINHO, 2005; DOWBOR, 2010). Nesse aspecto, poderia se constituir uma "gestão contra o social", que, conforme defende Maia (2005), se vincula aos processos de gestão no campo social, porém implementada a partir dos valores e propósitos pouco democráticos, distantes da ampliação da cidadania e difusores de uma abordagem extremamente tecnicista de gestão, além de alicerçar valores capitalistas. A partir desse foco, os valores $e$ propósitos do modelo de gestão adotado ficam facilmente identificados ao reconhecer o homem neste projeto como objeto e não sujeito desse processo, já que a centralidade da gestão residiria na técnica e no capital (MAIA, 2005). Em decorrência disso, os discursos e agendas de ação na esfera das políticas públicas, estratégias empresariais e iniciativas da sociedade civil reduziriam a magnitude de transformação do campo da Gestão Social ao traduzi-la em ações gerenciais na busca da eficiência e da eficácia de seus resultados.

A fim de clarificar e problematizar os significados que permeiam as temáticas que envolvem a Gestão Social segue adiante algumas contribuições acerca de seus pressupostos.

Alguns autores, como Tenório (2004, 2005), Boullosa e Schommer (2005), Gondim, Fischer e Melo (2006) e França-Filho (2008), destacam a abordagem da participação como elemento fundamental da Gestão Social. Dessa forma, "[...] a Gestão Social deve estar a serviço de muitos, de interesses sociais e do bem 
comum [...]", de forma que a identificação desses interesses, desejos e opiniões daqueles que pretendem servir a Gestão Social se constitui por meio da "[...] participação dos próprios beneficiários da gestão, em interação e por meio de relações dialógicas" (GONDIM; FISCHER; MELO, 2006, p. 70).

Ao utilizar a razão a partir do consenso alcançado por ação social baseada, sobretudo, na comunicação e no diálogo, evidencia-se a necessidade de acordos alcançados comunicativamente (TENÓRIO, 2004). Em outras palavras, a Gestão Social orienta-se para um processo de gestão no qual se evidencia a inclusão daqueles atores sociais que em outros contextos $e$ modelos de gestão são tomados como meros objetos, passivos no processo administrativo. Nesse processo caracteriza-se também a solidariedade como um dos motivos constitutivos da própria gestão, que se encontra em discordância com o que se manifesta, sobretudo em muitas das abordagens e intervenções gerenciais no universo das organizações empresariais privadas (TENÓRIO, 2005). "Enquanto na gestão estratégica prevalece o monólogo, o indivíduo, na Gestão Social deve sobressair o diálogo, o coletivo" (TENÓRIO, 2005, p. 36).

Nota-se que a abordagem da Gestão Social atrelada aos preceitos que incorporam a noção da participação contribui para os princípios que envolvem a emancipação social cuja base prevê o desenvolvimento do ser humano e, concomitantemente da própria sociedade na dimensão ambiental, econômica e cultural (CANÇADO, 2011). Percebe-se que essa perspectiva se apoia nos meios no qual ela se articula, configurando-se em processos. Porém, "[...] a ideia de Gestão Social orienta-se à gestão das demandas e necessidades do social" (FRANÇA-FILHO, 2008, p. 29), conferindo a ela a noção de fim ou como uma finalidade a ser alcançada. Esse escopo surge no seio da modernidade em uma sociedade onde a esfera econômica desempenha efetivamente um papel determinante, já que se vive em uma sociedade do trabalho e onde o social é identificado como um dos espaços do não trabalho (FRANÇA-FILHO, 2008). Nesse âmbito, Gestão Social confunde-se com gestão pública, pois compete tradicionalmente ao Estado o atendimento às demandas e necessidades da sociedade (FRANÇA-FILHO, 2008).

Essa noção, motivo de críticas de diversos autores da área, como França-Filho (2008), Pinho (2010),
Fischer (2008), Tenório (2004), permite orientar a discussão da Gestão Social para um novo paradigma de interação entre Estado e sociedade (BOULLOSA; SCHOMMER, 2005). Um modelo no qual o Estado revê sua suposta primazia na condução de processos de transformação social e assume a complexidade de atores e de interesses em jogo como definidora dos próprios processos de significação e construção de bens públicos. A partir dessa visão, o público corresponde a um espaço de interações entre diversos interesses que, articulados, definem valores comuns, envolvendo os direitos dos cidadãos e sua participação na gestão (BOULLOSA; SCHOMMER, 2005; GONDIM; FISCHER; MELO, 2006).

Além dessa aproximação teórica, observa-se que o termo Gestão Social se insere nos debates sobre a noção de desenvolvimento social, sendo percebida como um espaço "[...] reflexivo das práticas e do conhecimento constituído por múltiplas disciplinas [...]", permitindo significar a Gestão Social como gestão "[...] orientada para o social (como finalidade) pelo social (como processo), norteada pelos princípios da ética e da solidariedade" (FISCHER; MELO, 2006, p. 17). O local torna-se a esfera por excelência da Gestão Social, e essa articulação para vingar precisa da construção de estruturas de governança, com significativa participação da sociedade local, configurando um novo modo de se tecer o desenvolvimento (CARRION; CALOU, 2008, p. 17).

Os espaços intersticiais no qual se observa o desenvolvimento social são demarcados por organizações com múltiplas configurações que, segundo Alves (2002) e Teodósio (2010), são de natureza híbrida. Essas organizações, constituídas da conexão da sociedade civil, Estado e mercado, ao mesmo tempo em que ganham identidade se tornam peças estratégicas no jogo dos chamados poderes espacialmente localizados (FISCHER; MELO, 2006).

Suas características em relação ao tamanho, grau de formalização, volume de recursos, objetivos institucionais e forma de atuação variam. Mas, nota-se um consenso vinculado ao poder da auto-organização, da transformação de suas estruturas e estratégias e da regulação de seu próprio destino (MARTELLETO, 1997).

A identificação com a ética do bem comum e o uso do espaço público como contexto de referência, são outros atributos preponderantes na formação dessas organizações, 
que permitem a elas serem interlocutoras importantes no campo das políticas públicas e das ações de desenvolvimento socioterritorial (FISCHER; MELO, 2006).

Sem incorrer o risco de reduzir as organizações da sociedade civil ao campo de ação denominado terceiro setor, este espaço no qual se reconhece a atuação dessas organizações é constituído por "[...] agentes de natureza privada que praticam ações visando a fins públicos" (ALVES, 2002 p. 2). As organizações do terceiro setor teriam características polivalentes, incluindo fatores políticos e sociais. Seriam organizações híbridas e mesclariam recursos e racionalidades de diversos setores (EVERS, 1995). Em ambientes de políticas públicas caracterizadas pelo pluralismo, enfatiza-se no terceiro setor, a mistura sinergética de recursos e de racionalidades, e passam para o plano secundário os processos de mera substituição de uns setores por outros na promoção de serviços e bens públicos (ALVES, 2002).

Essa definição atribui ao terceiro setor um sentido dialógico que, segundo Tenório (1999, p. 18), deve atuar numa

[...] perspectiva comunicativa, na qual suas ações seriam implementadas por meio da intersubjetividade racional dos diferentes sujeitos sociais a partir de esferas públicas em espaços organizados da sociedade civil, a fim de fortalecer o exercício da cidadania deliberativa.

Apreende-se que, essa perspectiva associada a uma diversidade de atores que se organizam em prol do interesse comum, na busca de soluções para os problemas sociais, pode ser observado como um processo fundamentado pelos preceitos que ancoram a Gestão Social.

Além dos aspectos que envolvem as organizações da sociedade civil, se observa, como premissa da Gestão Social, a ideia de responsabilidade social. Demarcada pela conscientização dos gestores como cidadãos envolvidos nos problemas sociais, a vontade de colaborar com a sociedade na qual se inserem sobressai a expectativa de vantagens para a organização que dirigem (PINTO et al., 2008).

Observa-se outra vertente que destaca a responsabilidade social da empresa caracterizada pelo o interesse da administração em tomar decisões e ações que irão contribuir para o bem-estar da sociedade e da organização. Ou seja, a responsabilidade dos dirigentes da empresa não se restringe exclusivamente à gestão do negócio para a obtenção do lucro, mas também a respectiva influência de suas ações no âmbito social.

Makover (1994) corrobora esta ideia ao afirmar que uma empresa socialmente responsável procura ter uma visão de que tudo que ela faz gera uma variedade de impactos diretos $e$ indiretos dentro $e$ fora dela, atingindo desde os consumidores e empregados até a comunidade e o meio ambiente. Por definição, a responsabilidade social empresarial ancora-se na noção de que as corporações possuem a obrigação de trabalhar para a melhoria do bem-estar social (FREDERICK, 1994).

Destaca-se que essa perspectiva coloca as organizações em uma posição central de evidência na qual destacam os seus interesses. Nesse aspecto, a sociedade deixa de ser o ator principal na relação com as empresas e outros setores, precedendo a uma hierarquia de poderes vinculados a lógica do mercado.

Outra dimensão organizacional na qual a literatura brasileira atribui aspectos de cunho social, do bem coletivo e de articulação entre múltiplos atores é o da economia solidária, entendida como o ressurgimento de práticas solidárias entre trabalhadores sob o capitalismo (SINGER, 2000). Para Costa e Carrion (2006), a desigualdade insustentável da contemporaneidade, conforme qualificou Boff (2001), vem sensibilizando atores sociais de distintas ideologias em torno de propostas alternativas de desenvolvimento, cenário esse no qual se institui a perspectiva de uma economia solidária, como vetor de um desenvolvimento alternativo à ideia clássica capitalista.

França-Filho e Laville (2004) compartilham desta ideia ao reconhecerem a economia solidária como o entrelaçamento entre os campos econômicos e políticos.

Desse enlace a solidariedade entre os indivíduos não dispensaria a participação estatal, mas esta última estaria articulada à sociedade civil, que não seria um apêndice das políticas, possuindo autonomia e identidade própria. (CORDEIRO NETO et al., 2011, p. 176)

A dimensão política conferida à práxis da economia solidária permite recorrer às discussões acerca da Gestão Social, uma vez que se pretende inserir o sujeito como fator central nas relações. 
Ao identificar as temáticas que envolvem os pressupostos da Gestão Social foi possível evidenciar alguns processos que configuram sua prática, bem como suas proposições, porém, sem delimitá-la rigidamente. A Figura 1 "Gestão Social: Campo em construção, temas em evidência" apresenta, de forma sintética, as dimensões conceituais abordadas sobre a Gestão Social, o qual foi ilustrado por meio de linhas tracejadas para demonstrar o campo em construção em que ela se constitui.

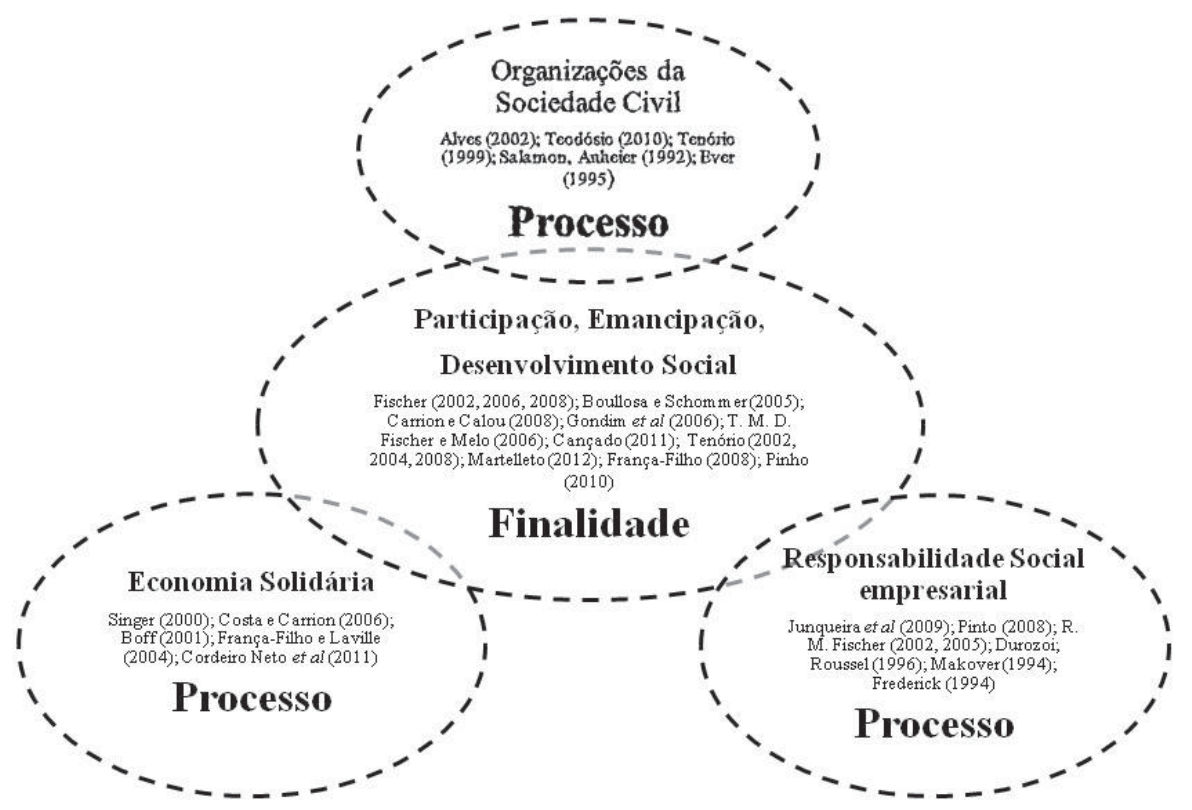

Figura 1: Gestão Social - Campo em construção, temas em evidência

Fonte: Elaborada pelos autores deste artigo

Destaca-se na Figura 1 uma sobreposição dos temas que expressam a Gestão Social a fim de contemplar a integração conceitual existente entre eles. A partir desse arcabouço conceitual é possível vislumbrar processos de gestão social heterogêneos, orientados para um fim comum, representados pela noção de participação, emancipação e desenvolvimento social. Essa perspectiva aponta uma construção mediada por múltiplos saberes que contribui para a sua pluralidade discursiva e para a constituição de um campo híbrido, no qual o aspecto econômico deixa de ser uma prioridade, acentuando-se a centralidade na dimensão política (SCHOMMER; FRANÇA-FILHO, 2008).

Salienta-se que, "[...] na gestão e, especialmente na Gestão Social, estão compreendidas muitas formas de aprendizagem" (SCHOMMER; BOULLOSA, 2010, p. 16).

Por outro lado,

[...] na aprendizagem estão presentes as formas da gestão, por se tratarem ambas de atos integradores entre pessoas que detém, em um determinado momento, em um espaço delimitado, poderes assimétricos sobre resultados desejados e sobre os itinerários a escolher. (SCHOMMER; BOULLOSA, 2010, p. 16)
Nesse cenário, destaca-se o ensino, a pesquisa e a extensão, elementos constituintes da universidade contemporânea, as quais, por meio de Centros e Programas de Estudos vêm implementando e disseminando os preceitos da Gestão Social. Tais Centros e Programas de Estudos são objeto de estudo deste trabalho ao se considerar as dinâmicas que contribuem para a prática dialógica e reflexiva.

A próxima sessão apresentará a pesquisa realizada junto aos seis Centros e Programas de Estudos que teve como premissa analisar as possibilidades dialógicas e reflexivas para o ensino e a pesquisa de Gestão Social no Brasil a partir da atuação dessas unidades de análise.

\section{Estratégias Metodológicas}

Os procedimentos metodológicos deste trabalho basearam-se na pesquisa qualitativa por compreender que ela permitiria, por meio da relevância que dá aos dados empíricos contrastados com as suposições teóricas, condição para se discutir as possibilidades 
dialógicas e reflexivas para o ensino e a pesquisa de Gestão Social no Brasil a partir da atuação de Centros e Programas de Estudo deste campo no país.

A unidade primária de análise, definida com base na pergunta de pesquisa (YIN, 2007), foi "dialogicidade e reflexividade" e "Gestão Social". Os dados empíricos foram coletados em pesquisa de campo realizada entre o período de 2013 a 2014, com seis Centros e Programas de Estudo do campo da Gestão Social no Brasil e tiveram apoio da pesquisa documental a qual se ancorou nos sítios eletrônicos, artigos e livros publicados de cada unidade de análise investigada. A seleção das unidades de análise foi baseada tendo-se a teoria abrangente como o critério de avaliação (YIN, 2007; GASKELL, 2002), visto que, tais unidades se despontam pelo ensino e pesquisa alicerçado pela égide dos preceitos que conduzem a Gestão social.

Os Centros e Programas de Estudo selecionados foram: o Centro de Empreendedorismo Social e Administração do Terceiro Setor (CEATS), do Departamento de Administração da Faculdade de Economia, Administração e Contabilidade da Universidade de São Paulo (FEA/USP); o Centro de Estudos em Administração Pública e Governo (CEAPG), pertencente à Escola de Administração de Empresas de São Paulo (EAESP), da Fundação Getúlio Vargas (FGV); o Programa de Estudos em Gestão Social, vinculado à escola Brasileira de Administração Pública e de Empresas da Fundação Getúlio Vargas (PEGS/EBAPE/FGV); o Centro Interdisciplinar de Desenvolvimento e Gestão Social da Universidade Federal da Bahia (CIAGS/UFBA); o Núcleo Interdisciplinar de Pesquisas e Estudos Sobre o Terceiro Setor da Universidade Federal do Rio Grande do Sul (NIPETS/UFRGS) e o núcleo de Estudos de Administração do Terceiro Setor da Pontifícia Universidade Católica de São Paulo (NEATS/PUC-SP).

A fim de manter sigilo, foram codificados os nomes dos entrevistados, de modo que todos receberam o código $\mathrm{ACAD}$ e um número que corresponde o Centro e Programa de Estudo em análise.

As entrevistas de profundidade foram realizadas com os respectivos fundadores e coordenadores dos Centros e Programas de Estudo, com duração média de uma hora e meia cada. Procurou-se, nesse processo, identificar e explorar: I) a influência do contexto sociopolítico na formação e desenvolvimento dos Centros e Programas de Estudos investigados; II) As práticas de ensino e pesquisa que emergem dos Centros e Progra- mas de Estudos investigados associadas a compreensão que os investigados detêm sobre os elementos objetivos e subjetivos que compõem a Gestão Social.

\section{Análise dos Dados}

A discussão inicial abrangeu a categoria de análise relativa à influência do contexto sociopolítico na formação e desenvolvimento dos Centros e Programas de Estudos investigados. Nessa perspectiva, vale destacar um contexto marcado pelos movimentos sociais reivindicatórios dos anos 1980 e 1990, os quais constituíram o cenário de formação e desenvolvimento dos Centros e Programas de Estudos.

Esse período, caracterizado por Gohn (1995) como dois momentos de associativismo brasileiro, evidenciou um conjunto de práticas que se traduziram numa cultura de cidadania. Segundo a autora, era algo "[...] novo num país de tradição centralizadora, autoritária, patrimonialista e clientelística. As ações abriram espaço que demarcaram novos lugares para a ação política, especialmente ao nível do poder local" (GOHN, 1995, p. 63).

Tais movimentos decorreram de organizações da sociedade civil que, em 1980 geraram um cenário de grande participação civil, seguido pela criação de espaços de interlocução entre o Estado e a sociedade civil e pela transição democrática no país (GOHN, 1995). Esse advento, apoiado pela promulgação da nova Constituição brasileira, orientou-se para a união da democracia direta para a democracia participativa que tinha como intuito a

[...] participação na definição das formas de gestão dos equipamentos e serviços, a definição da implantação das Leis Estaduais e Municipais, a construção dos diferentes Conselhos e Câmaras de interlocutores do Estado com a sociedade. (GOHN, 1995, p. 64)

A perspectiva de inserção no Estado por meio de canais interlocutores e participativos da sociedade civil e o surgimento ou renascimento de novas lutas sociais de caráter cívico, bem como a criação das redes de economia informal ou comunitária, determinou a mudança no tipo predominante de associativismo nos anos de 1990 (GOHN, 1995; MARTELETO; RIBEIRO, 1997; FISCHER; MELO, 2006). 
Mediante esse cenário observou-se um alinhamento da trajetória inicial de todos os Centros e Programas de Estudos investigados com as perspectivas que estavam sendo desenhadas no contexto sociopolítico do Brasil.

Segundo a fundadora e coordenadora do CEATS, o surgimento do Centro e Programa de Estudo se deu a partir de uma observação constante e sistematizada de movimentos da sociedade civil que vinham se organizando e adquirindo CNPJ, tal como as organizações sem fins lucrativos dos Estados Unidos (Entrevistada ACAD 2).

\section{[...] Com todas essas ideias de terceiro setor que eu observava nos Estados Unidos, aí eu disse: bom, temos que encontrar essas organizações e criar projetos onde elas se liguem com o governo, com empresas locais para o desenvolvimento local. Veja que interessante né, surge o conceito de parceria de alianças estratégicas e isto é mais ou menos em 1991 e 1992, estes projetos toma- ram um corpo muito forte dentro da faculdade onde nós resolvemos criar um espaço de estudo do terceiro setor e foi assim que surgiu o CEATS (Entrevistado ACAD 2).}

Essa percepção adicionada ao crescente número de organizações do terceiro Setor no Brasil, desde meados dos anos de 1980, refletiu no "[...] reconhecimento da magnitude e da importância que o terceiro setor vinha adquirindo no universo das organizações que conformam a sociedade contemporânea" (SCAICO, 1997, p. 74). Com o aumento da demanda de apoio consultivo, palestras e conferências dos docentes, assim como no desdobramento do interesse dos pesquisadores por esse fenômeno organizacional, em 1997, o CEATS foi concebido não somente com o intuito de "[...] nuclear atividades acadêmicas e científicas, mas também para, concomitantemente, dinamizá-las sob a forma de serviços e produtos que atendessem às necessidades da comunidade" (SCAICO, 1997 p. 74).

Agregado a sua formação profissional, que teve origem na escola de Ciências Sociais da USP e na inserção em comunidades vulneráveis, a entrevistada relatou que teve a oportunidade de oferecer projetos de consultoria através da Fundação Instituto de Administração (FIA) para trabalhadores boia frias nas agroindústrias o qual "eram projetos como consultoria que realmente faziam a mudança acontecer" (Entrevistada ACAD 2).
Nessa perspectiva, ela observou que "[...] não estava estudando teoria da responsabilidade social" (Entrevistada ACAD 2). Como estava trabalhando com os usineiros e com donos de indústria, mostrando a eles que, ao terem responsabilidade com os seus empregados, eles teriam mais vantagens do que desvantagens (Entrevistada ACAD 2), foi possível notar um processo de mediação orientado para a integração de interesses o qual convergia para a sustentabilidade do trabalho.

O CEAPG/FGV, outra unidade acadêmica observada sob esse aspecto, fundou-se a partir de um contexto no qual se aglutinavam ideias que iam além da administração das políticas públicas. Conforme o relato do professor fundador desse Centro e Programa de Estudo, a Administração pública ampliava o discurso para outras formas de relacionamento com a sociedade civil, "[...] não era só administração pública e governo, era muito mais amplo" (Entrevistado ACAD 4). Essa perspectiva, associada a um novo curso de mestrado em Administração Púbica e Governo oferecido pelo CEAPG/FGV, contribuiu para que esse curso, a partir de 1989, orientasse os seus propósitos para questões que contemplassem a governança pública com foco no desenvolvimento local e na garantia de direitos da cidadania.

Quanto ao CIAGS/UFBA, o seu processo de ensino e pesquisa sobre a Gestão Social, iniciou inspirado nos ideais de uma comunidade solidária que era liderada por uma pessoa aberta e que dialogava com todas as correntes de movimentos políticos e populares, a professora Ruth Cardoso (Entrevistada ACAD 10). Sob essa perspectiva, o Centro e o Programa de Estudo se consolidaram como espaços de articulação entre saberes teóricos e práticos, voltados para a promoção e aproximação entre discentes, professores e pesquisadores de Gestão Social com o Estado, a sociedade civil e empresas.

Já o NEATS/PUC-SP foi influenciado pelo interesse de alunos da PUC/SP que vinham observando um movimento de estudos e pesquisas na USP sobre o Terceiro Setor. Em 1998, o núcleo de estudo surgiu mobilizado por alunos e professores da PUC/SP empenhados em melhor compreender a sistemática do Terceiro Setor. Cadastrado desde 2000 no CNPQ com as linhas de pesquisa Gestão de Organizações Sem Fins Lucrativos, Gestão Social e Terceiro Setor, esse núcleo de estudo tem por objetivo realizar pesquisas, 
atividades de formação e de consultoria, produzir e difundir conhecimentos, articular redes e apoiar a gestão de organizações do Terceiro Setor, bem como a gestão das políticas sociais.

O NEATS/PUC/SP iniciou as suas atividades com o objetivo de discutir sobre o Terceiro Setor, tendo como pano de fundo a intersetorialidade. Esse aspecto vincula-se a formação profissional do fundador e coordenador do núcleo de estudo que teve participação em processos de políticas públicas no setor da saúde no qual desenvolveu tentativas de integração com outras áreas do poder público. Nota-se que essa habilidade se espelhou na constituição do núcleo de estudos que hoje abrange grupos interdisciplinares de administradores, advogados, psicólogos, sociólogos e de praticantes do Terceiro Setor. Segundo o entrevistado,

O nosso grupo é aberto. Nós trabalhamos com pesquisas, buscamos temas e financiamento. Estamos trabalhando também com editorial interinstitucional. Estamos também participando desta questão de Gestão Social com o grupo lá da Bahia, o observatório da Rosana. Fizemos no ano passado, pelo NEATS, o congresso do Enapegs e participamos do PRÓ-ADM (Entrevistado $A C A D$ 6).

O PEGS da EBAPE/FGV foi outro programa o qual teve como ponto de apoio a habilidade social de seu coordenador. Defensor de uma linha de pensamento no qual o mercado não é um determinante, ele introduziu "[...] temáticas de responsabilidade social vinculada à questão da sustentabilidade e governança nas discussões da gestão pública" (Entrevistado, ACAD 9).

Conforme o entrevistado,

[...] a intenção era manter aquela preocupação anterior da sociedade com o estado, por meio da cidadania e eu pensei a mesma coisa em relação ao mercado. Então, daí veio a ideia de criar o grupo de estudos para a Gestão Social, em 1990. Junto a isso eu já vinha trabalhando um projeto com comunidades aqui do Rio de Janeiro e isso facilitou a discussão (Entrevistado ACAD 9).

Observa-se que a iniciativa do coordenador foi essencial para que o PEGS se consolidasse como um programa cujo objetivo centra-se nas discussões da sociedade como fator central nas relações com o mercado e com o Estado.
A ideia foi manter aquela preocupação, que também é uma preocupação de outra linha de pensamento existente, como é o pessoal Frankqfurtiano ou próprio Guerreiro Ramos, que vai discutir a necessidade de você pensar a sociedade determinando as demais relações (Entrevistado ACAD 9).

O outro Centro e Programa de Estudo no qual foi possível notar as influências do contexto sociopolítico na sua formação foi o NIPETS/UFRGS. Observou-se que os objetivos iniciais e atuais do Centro e Programa de Estudo contemplam a trajetória de formação acadêmica e profissional da coordenadora a qual é formada em sociologia e em administração na área da sociologia das organizações. Orientada pela temática que envolve a construção democrática em contexto local $e$ internacional por perceber que as questões sociológicas no âmbito do trabalho não conseguiam respostas, as ações do NIPETS orientam-se para fatores sociais que se relacionam com o Terceiro Setor, porém, de forma mais abrangente. Essa perspectiva é possível de ser verificada no relato da entrevistada.

Ele surge no programa de pós-graduação trabalhando com as questões de inclusão social, de pobreza, desigualdade, politicas sociais $e$ desenvolvimento para tentar entender elementos da economia solidária por exemplo. Uma linha, eu diria que hoje o NIPETS está voltado para a questão da compreensão de um lado de como se dá o processo de reconstrução e inclusão de países de extrema precariedade, como no caso do Haiti e da Bósnia. Como se dá a reconstrução democrática! Isso esta muito mais voltado para a questão da democracia do que Terceiro Setor, entende? Num país como o Haiti, que tem uma crise brutal, um país como Cabo Verde, por exemplo, um país onde se tinha pobreza, mas não tinha miséria e este país entra de uma forma assim, avalanche, no termo do capitalismo globalizado. Como a sociedade reage? Então, é a sociedade frente ao Estado com as suas políticas de inclusão. E aí entrando também, as agencias internacionais de cooperação, e aí também as ONGs, supervoltadas para a questão dos movimentos sociais, mas tudo isso se articulando com o plano do local. Local no internacional (Entrevistada ACAD 7). 
Observa-se que os Centros e Programas de Pesquisas investigados tiveram a sua constituição marcada pelos princípios que norteiam as discussões sobre a Gestão Social. Entre eles, destacam-se o interesse em estudar os processos de participação e de possibilidades de desenvolvimento social oriundos das articulações entre o Estado, sociedade e mercado, no qual se percebe uma forte presença das organizações da sociedade civil. Acredita-se que esses aspectos refletem possibilidades de diálogo e reflexão nas dinâmicas de ensino e pesquisa propostas pelos Centros e Programas de Pesquisas.

A outra categoria proposta por este trabalho para analisar as perspectivas de ensino e pesquisa que contribuem para a prática dialógica e reflexiva baseou-se na compreensão que os investigados detêm sobre os elementos objetivos e subjetivos que compõem a Gestão Social a partir das dinâmicas e articulações provenientes dos Centros e Programas de Estudos.

Um primeiro aspecto realçado pelos atores e que se julgou de extrema relevância, por nele apresentar a base para se dinamizar as proposições que envolvem a Gestão Social, foi a ideia de que os problemas sociais, políticos e econômicos não são de responsabilidade de um setor ou de uma esfera só, são de todos, de modo a incidir em soluções compartilhadas. Essa primeira compreensão permite integrar à Gestão Social os pressupostos que envolvem as abordagens relativas à visão intersetorial.

Além dessa inferência, apreende-se que a noção intersetorial conduz a ideia de interdisciplinaridade, devido à necessidade de envolver campos de conhecimento diferentes que, se interagem de forma convergente ou divergente, com o intuito de ampliar as possibilidades de enfrentamento às questões sociais impostas.

Destaca-se que, todas as amostras analisadas apresentaram no escopo de sua atuação relações com diversos setores sociais, implicando em ações e articulações intersetoriais.

Uma das coordenadoras do CEATS/USP exprimiu a ideia de integração entre atores de diversos setores em prol de objetivos comuns ou paralelos, ao evidenciar uma das propostas do Centro e Programa de Estudo associada à visão intersetorial.

A fundadora do CEATS sempre teve uma discussão na sociologia. E quando ela entra na
Administração ela vai para o campo da gestão de pessoas, da cultura e poder. É quando ela vê a oportunidade de maior integração entre órgãos públicos, sociedade civil e também a contribuição de empresas no desenvolvimento sustentável. Então, é um campo novo que foi surgindo muito por uma observação empírica e que foi estimulado por alguns financiamentos internacionais que começaram a incentivar a intersetorialidade (Entrevistada ACAD 1).

Em sintonia com essa perspectiva de atuação, a noção expressada sobre Gestão Social comunga com os aspectos que enseja a ideia de ações intersetoriais.

Olha, eu acho que tem um reconhecimento de que a problemática social não é um problema de um único ator, é a reversão da pobreza. $O$ que é pobreza e como eu reverto situações de desigualdades é um problema coletivo, é um problema de todos nós. Como é um problema de todos nós, ninguém é onipotente, ninguém é dono da solução. Então, as soluções elas partem de um trabalho colaborativo, quem colabora com quem. Então, acho que tem o reconhecimento do esgotamento do Estado, no sentido dele conseguir sozinho dar conta, embora, seja premissa de um direito de você ter acesso à educação, à saúde ou à moradia. Mas de fato, ele nasceu dessa capacidade de provisão? Então, se é incapaz, ao invés da gente ficar discutindo isso, por que não pensamos em como os outros atores podem de fato contribuir para essa questão, que é também um problema deles, não só um problema do Estado. O maior avanço que eu vejo é de você incluir a temática de Gestão Social na pauta de todos os atores. Assim como em atores mais alienados, como eram as empresas, onde já há um reconhecimento que a própria sobrevivência da empresa passa por um olhar do que esta acontecendo em torno, em como ela lida com os diferentes setores. Então ela também vai procurar a dimensão do social. A gente pode criticar que é muito lenta e que, às vezes, é só superficial, mas que há um reconhecimento de que todos devem agir, de que todos são culpados e que todos de alguma maneira são responsáveis pela solução há. Então, Gestão Social e a responsabilidade social são incorporadas como um valor da sociedade (Entrevistada ACAD 1). 
Nota-se que essa visão incidiu nas atividades desenvolvidas pelo CEATS/USP o qual, segundo a entrevistada, teve relevante participação na criação de uma rede de pesquisadores Ibero-americana, o Sken, de iniciativa de um professor da universidade de Harvard. "Essa rede foi muito interessante por que foi uma forma de sair desse mundo, dessa realidade brasileira, onde os problemas são continentais, que pouco se basta com o um único olhar" (Entrevistada, ACAD 1).

Essa perspectiva permitiu ao CEATS/USP integrar seus trabalhos a eixos de pesquisas orientados pelo Sken o qual contemplava um "[...] olhar daquilo que acontecia no Brasil concomitantemente, direcionado para aquilo que insurgia na América Latina e que era emergente no campo social" (Entrevistada ACAD 1). O primeiro eixo de pesquisa desenvolvido foi Alianças Intersetoriais, o segundo eixo foi a Gestão de Empreendimentos Sociais e o terceiro Negócios Inclusivos.

A fundadora e também coordenadora do CEATS/ USP, ao relatar o surgimento do Centro e Programa de Estudo apontou as mesmas demandas de trabalho interdisciplinar orientada para o Terceiro Setor por meio de parcerias com governo e empresas locais e, posteriormente, através da associação com o Sken, no período de 2001 a 2002.

Destaca-se que essa associação ocorreu quando - CEATS/USP já havia acumulado uma experiência de 10 anos de trabalho com ONGs como o Instituto Ethos, o GIFE e pesquisas realizadas para Fundação Ford, o qual lhe rendeu um patrimônio de conhecimento, incentivando o convite da Harvard. "O propósito era contribuir na formação de um Network de empresas que pudesse construir conhecimento sobre, inicialmente, parcerias entre empresas com responsabilidade social e organizações sem fins lucrativos" (Entrevistada ACAD 2, 2013).

Esse propósito possibilitou uma pesquisa comparativa com outros países associados ao Sken que, por estarem trocando informações, rendeu-lhes um senso de realidade para saber como caminha o ensino, a pesquisa e mesmo a consultoria dentro destes temas (Entrevistada ACAD 2).

Infere-se que, a proposta de criação do CEATS/ USP integrada à perspectiva da visão intersetorial $e$ fomentada, posteriormente, pela parceria com o Sken, demonstra processos de ensino e pesquisa conduzidos pela integração dialógica e reflexiva impulsionada pela socialização de experiências e pesquisas entre os países associados, os quais refletiram em suas dinâmicas.

O relato de um dos fundadores do CEAPG/FGV sobre as parcerias que são firmadas entre atores de diferentes organizações demonstra um apelo crítico ao inserir os aspectos que envolvem a definição sobre saberes híbridos como útil até certo ponto. "O que está em questão é a interface entre duas espécies que são distintas sem haver a sobreposição de uma sobre a outra" (Entrevistada ACAD 4). Nesse sentido, ele apresenta como exemplo as práticas organizacionais de empresas privadas e estatais ao ofertarem "[...] cursinhos para as organizações sociais aprenderem a preencher os formulários da prefeitura" ou outro mecanismo de atuação que elas podem vir a ter (Entrevistado ACAD 4).

É aquela coisa, quero ser bonzinho e captar dinheiro da prefeitura para a nossa empresa. Ao invés de você dizer, escuta, eles tem uma maneira de organização, porque se não, eles não estariam lá. Nós temos uma maneira de organização, nós temos que criar um terceiro espaço que não subordina nem $A$ e nem $B$, mas que permite um contato com $A$ e $B$ e que atenda as diferentes que são importantes para eles sem perder a sua entidade. Isso é trabalhar junto, e esta é a grande questão. Onde estão estes trabalhos (Entrevistado ACAD 4).

A intersetorialidade também pôde ser observada nas dinâmicas e articulações conduzidas pelo CEAPG/ FGV cujo ensino e pesquisa e a noção que envolve a Gestão Social se instituem a partir das relações que são estabelecidas entre os atores e organizações objeto de estudo e de assistência prática do Centro e Programa de Estudo.

Ela tornou-se evidente no Programa de Gestão Pública e Cidadania criado em 1995, que tinha como objetivo premiar as práticas inovadoras na gestão pública subnacionais dos governos brasileiro. Estruturado em rede por pesquisadores em torno do Brasil, envolvendo atores de organizações não governamentais, governos e universidades, as pesquisas se efetivavam no local investigado, conduzidas por um roteiro de entrevista (Entrevistado ACAD 4). Segundo o entrevistado, o interesse em compreender o propósito e, sobretudo, em saber quais secretarias ou órgãos do governo estavam 
envolvidos no projeto foi o elemento propulsor para entender as dinâmicas que emergiam de suas práticas.

A pesquisa baseada nesses argumentos demonstrou que, somente em $20 \%$ dos casos a atividade que estava sendo comunicada a eles era realizada por uma única repartição pública sobre o clássico "eu e o meu projeto" (Entrevistado ACAD 4). Nos demais $80 \%$ dos casos, havia outras organizações públicas, organizações da sociedade civil ou ambos envolvidos nas dinâmicas propostas.

Para o fundador e ex-coordenador do CEAPG/ FGV, a "[...] necessidade demonstrada em elaborar contatos, relações, apoios, construindo redes de relações que, mais tarde seriam reconhecidos como parcerias ou coisas assim, foi o que mais chamou atenção do grupo" (Entrevistado ACAD 4).

Associado a isso, outro fator destacado refere-se ao perfil das organizações da sociedade civil parceiras dos programas ou projetos públicos.

Elas não eram as ONGs ou as novas formas organizacionais sociais das empresas que estavam e ainda continuam interessadas nos seus próprios projetos do que nos projetos dos outros. Elas eram organizações locais de base, pequenas empresas como as organizações religiosas, sindicatos e associações sindicais de trabalhadores agrícolas, associações comerciais, de moradores e algumas vezes as universidades locais (Entrevistado ACAD 4).

Mediante esse quadro o entrevistado chama atenção para o modo como os acadêmicos do campo da Gestão Social observam as organizações de base de fé que, segundo ele, não são apontadas nos estudos. Para ele, essas organizações que não são de cunho religioso, mas sim, de base composta pela fé e, que, por isso, chamam as pessoas para junto, são de extrema relevância para se compreender, por exemplo, o cenário de 1970 até os dias de hoje (Entrevistado ACAD 4).

Mediante os aspectos apresentados acerca das práticas que conduzem o ensino e a pesquisa do CEAPG/FGV foi possível observar processos que se vinculam ao diálogo e a reflexão sustentados a partir do que os atores envolvidos tinham a oferecer e ao considerarem os locais e o território de sua constituição como espaços de inovação (Entrevistado ACAD 3).

Salienta-se que a noção de território também circunda os trabalhos desenvolvidos pelo CIAGS/UFBA cujas premissas abrangem a noção de Gestão Social intercedida pelos aspectos da intersetorialidade.

Conforme os dados secundários obtidos pelo site do centro de estudo, este é um espaço no qual se busca o desenvolvimento socioterritorial mediante a criação de tecnologias sociais replicáveis, considerando os conhecimentos gerados pela qualificação de gestores do desenvolvimento social, nos âmbitos da graduação e pós-graduação.

Esse objetivo prevê uma aproximação entre discentes, professores e pesquisadores da Gestão Social com o Estado, a sociedade civil e as empresas por se compreender que o desenvolvimento territorial e da Gestão Social estão referenciados a um território que, por sua vez, expressa a construção cultural (Entrevistado ACAD 10).

Nesse sentido, a fundadora e coordenadora do CIAGS/UFBA apresenta o quadro de atuação do centro mediante um exemplo vivenciado por ela no qual relata a sua relação com o mundo do Estado, das políticas públicas, dos moradores líderes de comunidades baianas, das empresas privadas e dos alunos que os compõem, traduzindo-os em "[...] praticantes e interlocutores que alimentam o centro" (Entrevistada ACAD 10).

Eu tive uma reunião hoje de manhã com a prefeitura de Salvador, com pessoas que representam as secretárias, o secretário adjunto, o da administração e com outro grupo que esta trabalhando com a recuperação de espaços públicos, como as praças, especialmente aquelas que estão próximas das igrejas e dos terreiros de candomblé. Bom, depois eu estive em uma reunião com o secretário de administração que discutiu comigo a entrada da cidade de salvador no mestrado que oferecemos. Bom, ontem nós tivemos contato com esses representantes das prefeituras do interior. Ao mesmo tempo, teremos amanha e depois, outro encontro para um projeto que estamos desenvolvendo que é agitação de base a pedido da Caixa Econômica Federal para os Programas Minha Casa Minha Vida que vai ser uma escola digital para jovens que não estudam e nem trabalham. Nós vamos até lá nos relacionarmos com os praticantes de um desses empreendimentos. Enfim, nós vamos fazer uma primeira reunião com eles (Entrevistada ACAD 10).

Nota-se que as dinâmicas $e$ articulações que sustentam o CIAGS/UFBA vigoram em bases multi- 
disciplinares de interlocução intersetorial, evidenciadas por preceitos sociais que se desdobram por meio dos conflitos territoriais e atuais.

Essa perspectiva demarca a compreensão que o centro anuncia sobre a Gestão Social, amparada pela noção que ela "[...] não é a gestão da exclusão ou da pobreza, ela é a gestão da sociedade, e que precisa ser ressignificada conforme as demandas contemporâneas. Por isso é chamada de social" (Entrevistada ACAD 10).

A Gestão Social não é um voto ou um adjetivo que dure para sempre. Quando ele não for necessário, ele cai. Então, na verdade, a gestão social é um circunstancia. A não ser que a gente esteja absolutamente sempre sensível às novas demandas da gestão e da sociedade.É um problema não pensado e é um problema social, temos problemas novos. Estamos hoje com essa dificuldade de relacionamento mais sensível com os novos problemas da sociedade e pela a sociedade. Como que a sociedade se gere? E como é que nós pensamos nos diferentes territórios que constituem a sociedade, tanto físicos quanto virtuais (Entrevistada ACAD 10).

O NIPETS/UFRGS também agrega em seu plano de atuação a ideia de transformação dos problemas sociais, configurado por tensões que vão se alterando à medida que a sociedade vai evoluindo. Segundo a coordenadora do núcleo de estudos, hoje os questionamentos envolvem discussões sobre movimentos sociais e não mais sobre orçamento participativo. "As coisas vão se modernizando, antes se trabalhava com pobreza e agora com a desigualdade" (Entrevistado ACAD 7).

O PEGS/FGV ao ser instituído como um programa no qual se discute as relações da sociedade com o Estado e com o mercado por meio da cidadania, propõe, como base epistemológica, a interdisciplinaridade. Suas dinâmicas e articulações derivadas desse aspecto se efetivam em campos de conhecimento distintos à Administração, o que enuncia relações múltiplas entre setores da esfera social.

O relato do fundador e coordenador do programa elucida essa ideia ao significar a Gestão Social a partir de dimensões amplas e interdisciplinares por entender que, como ela se apoia na sociedade que é múltipla, somente um campo de conhecimento não conseguiria discuti-la em sua totalidade (Entrevistado ACAD 9).

Associado a esse princípio, o entrevistado aborda algumas questões críticas sobre a visão limitada desenvolvida por alguns acadêmicos sobre a Gestão Social. Para ele, quando as pessoas discutem a questão social permeiam muito a linha do assistencialismo, do terceiro setor com preocupações direcionadas às políticas públicas. "Quando discutimos Gestão Social no grupo, desde a década de 1990, é feito numa linha da democratização das relações sociais. $O$ assistencialismo, as políticas públicas e o terceiro setor fazem parte, mas o fundamento é que o social parte da interação das pessoas" (Entrevistado ACAD 9).

A partir dessa ideia sobre Gestão Social o programa desenvolve alguns projetos apoiados pela lógica de conhecimento socioprático. Um deles é financiado pela CAPES e é denominado de Gestão Social e Prática cujas dinâmicas operam em parceria com outras dez universidades para o desenvolvimento do tema "Território de Cidadania" (Entrevistado ACAD 9). Há o projeto que realiza um laboratório de transferência de tecnologia social com algumas comunidades do Rio de Janeiro. Nesse projeto, há um curso direcionado para a gestão comunitária e sustentabilidade. Há também outro destinado à formação de conselheiros municipais. Além dessas iniciativas, acrescentam-se as publicações de livros e artigos científicos (Entrevistado ACAD 9).

A perspectiva de se discutir as relações entre sociedade, Estado e mercado, como sendo o cerne da Gestão Social também norteia os trabalhos desenvolvidos pelo NIPETS/UFRGS.

Segundo a fundadora e coordenadora do núcleo de estudo os temas abordados concentram-se na reconstrução da democrática local e global para o estudo da reação da sociedade frente ao Estado e as suas políticas de inclusão vinculadas a agências internacionais de cooperação, as ONGs e aos movimentos sociais.

Para ela, a lógica social relaciona-se a uma situação global de problematização da democracia que se conecta com a questão da governança a qual ela questiona as possibilidades de se estudar diferentes atores. "O nosso debate é realmente de sociologia política, sempre voltada para o local" (Entrevistada ACAD 7).

Apreende-se que esse depoimento vigora nas linhas de pensamento dos outros atores investigadose citados, principalmente os coordenadores do CIAGS/ UFBA e do PEGS/FGV os quais desenvolvem uma abordagem sobre Gestão Social proveniente das situações locais, dos territórios integrados aos aspectos sociais de ordem democrática. Nesse eixo, é possível observar processos que demandam práticas intersetoriais que, por sua vez, remetem à interdisciplinaridade e a saberes híbridos, os quais merecem especial atenção para não serem conduzidos sob a ótica hegemônica, 
assim como proferiu o fundador do Programa de Gestão Pública e Cidadania do CEAPG/FGV.

A noção de Gestão Social expressada pelo coordenador do NEATS/PUC/SP se debruça na visão intersetorial $e$ interdisciplinar as quais envolvem ideia de coletividade. Para ele, a Gestão Social é todo processo de trabalho na área social com o objetivo de coletividade (Entrevistada ACAD 6).

O fundamental é o coletivo e pra mim política pública é isso, política social é isso, então você não pode falar que não tem a gestão. O que é gestão? É você mobilizar recursos para conseguir agir e trabalhar neste social. A questão pública ela se caracteriza por lidar com o coletivo, o bem público. Isso não vai ser outra coisa. O social é complexo, gerenciar isso é também difícil. Então, você tem que gerenciar e mobilizar para que as pessoas tenham uma qualidade de vida e isso passa pela forma que você olha a realidade $e$ lida com ela. Isso é uma questão fundamental, o coletivo social é o que interessa, a realidade social é o que interessa e, ser social é ser complexo (Entrevistado ACAD 6).

Adotando o princípio da coletividade, o conhecimento produzido pelas dinâmicas de trabalho do núcleo de estudo é aplicado em projetos direcionados ao terceiro setor de forma interdisciplinar. Como exemplo, ele cita um projeto concebido a partir de um edital do Ministério da Justiça no qual houve uma ampla integração entre o pessoal do Direito e da Administração, implicando em uma vasta repercussão (Entrevistado ACAD 6).

O nosso grupo é aberto. Nós trabalhamos com pesquisas, buscamos temas e financiamento. Estamos trabalhando também com editais interinstitucionais e participando desta questão da Gestão Social com o grupo do observatório da Rosana, na Bahia. Fizemos no ano passado, pelo NEATS, o congresso do ENAPEGS e participamos também do Pró-ADM, que foi mais com o pessoal da Administração porque ele é mais administração (Entrevistado ACAD 6).

O entrevistado também mencionou um curso de extensão ofertado pelo núcleo de estudo que é uma especialização direcionada a projetos sociais e organizacionais para o terceiro Setor cuja relevância o conduziu a formação de sete turmas. Há outras iniciativas no âmbito da extensão que são cursos menores de 20 horas e 60 horas para o campo das políticas públicas e para a educação destinada à sustentabilidade, bem como um curso chamado Introdução ao Terceiro Setor, de 40 horas, o qual é realizado aos sábados em parceria com o grupo comunitário da PUC/SP. "Este é o nosso forte, os cursos de formação" (Entrevistado ACAD 6).

O Quadro 1 apresenta os dados analisados de forma resumida a fim de melhor explicitar as discussões.

\begin{tabular}{|c|c|}
\hline $\begin{array}{c}\text { Categorias de } \\
\text { ANÁlise }\end{array}$ & Centros e Programas de Estudos \\
\hline $\begin{array}{l}\text { A influência } \\
\text { do contexto } \\
\text { sociopolítico } \\
\text { na formação e } \\
\text { desenvolvimento } \\
\text { dos Centros } \\
\text { e Programas } \\
\text { de Estudos } \\
\text { investigados. }\end{array}$ & $\begin{array}{l}\text { Todos demonstraram iniciar suas atividades } \\
\text { em um contexto marcado pelos movimentos } \\
\text { sociais reivindicatórios dos anos } 1980 \text { e } 1990 \text {. }\end{array}$ \\
\hline $\begin{array}{l}\text { As práticas } \\
\text { de ensino } \\
\text { e pesquisa } \\
\text { associadas à } \\
\text { compreensão } \\
\text { que os } \\
\text { investigados } \\
\text { detêm sobre } \\
\text { os elementos } \\
\text { objetivos e } \\
\text { subjetivos que } \\
\text { compõem a } \\
\text { Gestão Social. }\end{array}$ & $\begin{array}{l}\text { Todos apresentaram a ideia de que os } \\
\text { problemas sociais, políticos e econômicos } \\
\text { não são de responsabilidade de um setor ou } \\
\text { de uma esfera só, são de todos, de modo } \\
\text { a incidirem em soluções compartilhadas. } \\
\text { CEATS/USP } \\
\text { Integração com diversos atores e } \\
\text { setores de abrangência - continental } \\
\text { - Participação na rede SKEN. } \\
\text { CEAPG/ EAESP/FGV } \\
\text { Parcerias entre atores diferentes - armadilha } \\
\text { (sobreposição de conhecimentos) - } \\
\text { Programa de Gestão Pública e Cidadania. } \\
\text { CIAGS/UFBA } \\
\text { Gestão social não é gestão da exclusão } \\
\text { ou da pobreza, é a gestão da sociedade } \\
\text { - Espaços de criação de tecnologias } \\
\text { sociais aplicáveis, conhecimento } \\
\text { gerado pelos por gestores sociais. } \\
\text { NIPETS/UFRGS } \\
\text { Transformação e gestão dos problemas } \\
\text { sociais - sociologia política - Espaços } \\
\text { de discussão e conhecimento - } \\
\text { terceiro setor e visão mundial. } \\
\text { PEGS/EBAPE/FGV } \\
\text { Relações múltiplas entre setores da } \\
\text { esfera social - o mercado não é a esfera } \\
\text { principal - Programa Gestão Social e } \\
\text { Práticas, Laboratório de Transformação } \\
\text { Social e Formação de Conselheiros. } \\
\text { NEATS/PUC - SP } \\
\text { - trabalhos direcionados a projetos para } \\
\text { o terceiro setor - interdisciplinar. }\end{array}$ \\
\hline
\end{tabular}

Quadro 1: Síntese da análise dos dados

Fonte: Elaborado pelos autores deste artigo 
Observa-se, conforme mostra o Quadro 1, a influência do contexto sociopolítico das décadas de 1980 a 1990 na formação e no desenvolvimento dos Centros e Programas de Estudos investigados. O que influenciou nas práticas e dinâmicas do ensino e pesquisa das unidades de análise. Foi possível também perceber que essas práticas e dinâmicas se apoiam na intersetorialidade para a busca de soluções do bem comum. Essa perspectiva se aproxima das discussões sobre Gestão Social, uma vez que se pretende inserir o sujeito como fator central nas relações ao se considerar soluções comuns no âmbito do social. Nesse sentido, é notória a noção de desenvolvimento social ao elevar o espaço territorial como possibilidade de reflexão da prática e do conhecimento constituído. Tal proposição indica a interação entre atores híbridos que, mesmo amparada na lógica participativa, demonstrando dialogicidade e reflexidade nos processos de ensino e pesquisa, pode ser envolvida por vezes, pela hegemonia do conhecimento de um sobre outro. Esse aspecto evidencia um desafio a ser superado pelas unidades de análise por se sustentar no interesse individual e autoritário.

\section{Considerações Finais}

A perspectiva intersetorial observada como um meio para se exprimir as dinâmicas da Gestão Social, embute em seus preceitos noções coletividade, de interesse comum e de interdisciplinaridade por supor a interação entre campos de conhecimento distintos e constituídos de múltiplos saberes.

Observou-se que essa noção, decorrente do contexto sociopolítico vivenciado pelos atores investigados, contribuiu para a formação $e$ implementação de processos de ensino e pesquisa ancorados na dialogicidade e na reflexidade.

Os Centros e Programas de Estudos pesquisados apresentaram em suas práticas interações interorganizacionais mediadas pela consonância entre os atores envolvidos. Notou-se que as práticas de ensino $e$ pesquisa se expressam por meio da importância que se dá ao outro. Em outras palavras, os seus processos de produção de conhecimento se dão a partir das pessoas, dos locais, de modo a permite a recursividade do conhecimento sendo aplicado, validado, revisto $e$ criticado.
Todavia, vale destacar que a noção interdisciplinar configurada pela visão intersetorial foi anunciada por alguns dos acadêmicos como um desafio a ser superado ao enfatizar a necessidade de se reconhecer a concepção da Gestão Social atrelada a outros campos de conhecimento e de poder. E, principalmente, por nela residir saberes híbridos os quais demonstram sobreposição de uns sobre outros, ressaltando relações hegemônicas que limitam o diálogo e a reflexão para o campo do ensino da Gestão Social.

Apreende-se que este aspecto demonstra uma lacuna a ser preenchida por meio de estudos científicos que busquem estender a pesquisa sobre o campo da Gestão Social vinculado às relações que precedem a sua prática.

\section{REFERÊNCIAS}

ABRAMOVAY, R. Muito além da economia verde. São Paulo: Abril, 2012.

AKTOUF, O. Administração entre a tradição e a renovação. São Paulo: Atlas, 1996.

ALVES, M. A. Terceiro Setor: as origens do conceito. In: XXVI ENCONTRO NACIONAL DOS PROGRAMAS DE PÓS-GRADUAÇÃO EM ADMINISTRAÇÃO, Salvador: ANPAD 2002. Anais... Salvador, ANPAD. p. 1-15.

\section{ARAÚJO, E. T. (IN)Consistências da Gestão Social e}

seus processos de Formação: um campo em construção. 2012. 262 p. Tese (Doutorado) - Pontifícia Universidade Católica de São Paulo, São Paulo, SP. Brasil, 2012.

BOULLOSA, R. F.; SCHOMMER, P. C. Limites da Natureza da Inovação ou qual o Futuro da Gestão Social? In: XXXII ENCONTRO CIENTÍFICO DE ADMINISTRAÇÃO. Rio de Janeiro, 2008. Anais... Rio de Janeiro, Brasil, 2008. p. 65-92.

BOULLOSA R. F.; SCHOMMER, P. C. Gestão social: caso de inovação em políticas públicas ou mais um enigma de Lampedusa? In: III ENCONTRO NACIONAL DE PESQUISADORES EM GESTÃO SOCIAL, Petrolina (PE) e Juazeiro (BA), 2009. Anais... Petrolina (PE) e Juazeiro (BA), 2009. 
CANÇADO, A. C.; TENÓRIO, F. G.; PEREIRA, J. R. Gestão Social: reflexões teóricas e conceituais. Cadernos EBAPE BR, Rio de Janeiro, v. 9, n. 3, 2011.

CARRION, R. M.; VALENTIM, I. V. L.; HELLWIG, B. C. (Org.). Residência solidária: vivências de universitários com o desenvolvimento de uma tecnologia social. Porto alegre: UFRGS, 2006. 208 p.

CARRION, R. S. M. O Desafio de Desenvolver Competências em Gestão Social: relato da experiência com a Residência Solidária/UFRGS. In. SILVA JR. Jeová, T. et al. Gestão Social: práticas em debates, teorias em construção. Juazeiro do Norte: Laboratório Interdisciplinar de Estudos em Gestão Social - Universidade Federal do Ceará, 2008. p. 117-204.

CARRION, R. S. M.; CALOU, A. Prefácio. In: SILVA JR. J. T. et al. (Org.). Pensar a Gestão Social em Terras de "Padinho Cícero". Fortaleza: Imprensa Universitária, 2008.

\section{CHANLAT, J. F. Ciências Sociais e Management:}

reconciliando o econômico com o social. São Paulo: Atlas, 2000.

CORDEIRO NETO, J. R.; ALVES, C. L. B.; RIGO, A. S. O estado do Ceará no contexto da economia solidária brasileira: Aspectos de destaque e desafios aos EES Cearenses. In: RIGO, Ariadne S. (Org.). Gestão Social e Políticas Públicas de Desenvolvimento: ações, articulações e agenda. Juazeiro-BA/Petrolina-PE: editora UNIVASF, março de 2010. p. 171-206.

COSTA, P. A.; CARRION, R. M. (2008). Economia Solidária e Cidadania: um longo caminho a percorrer. In: CANÇADO, A. C. (Org.). Os desafios da formação em gestão social. Palmas/Tocantis: editora Provisão, 2008. p. 177-197.

DOWBOR, L. Da propriedade intelectual à economia do conhecimento. Economia Global e Gestão, Lisboa, v. 15, n. 1, abr. 2010.

DOWBOR, L. Políticas nacionais de apoio ao Desenvolvimento local: empreendedorismo local e tecnologias sociais. Revista de Administração Pública, [S.l.], v. 32, n. 2, p. 187-206, 2005.

DOWBOR, L. Tendências da Gestão Social. Saúde Sociedade, [S.1], v. 8, n. 1, p. 3-16, 1999.
DUROZOI, G.; ROUSSEL, A. Dicionário de Filosofia. 2. ed. Campinas: Papirus, 1996.

EVERS, A. Part of the Welfare Mix: the thir sector as an intermediate área. Voluntas, [S.I.], v. 6, n. 2, p. 159-182, 1995.

FISCHER, R. M.; FALCONER, A. P. Desafios da parceria Governo Terceiro Setor. Escola de Serviço Social da UFRJ, Rio de Janeiro, abril, 1998. Disponível em: < http://empreende.org.br/pdf/ONG's, \%20OSCIP'S\%20 e\%20Terceiro\%20Setor/Desafios\%20da\%20Parceria\%20 Governo\%20Terceiro\%20Setor.pdf>. Acesso em: 29 out. 2015.

FISCHER, T. M.; MELO. V. P. Projeto Programa de Desenvolvimento e Gestão Social. Edital MCT/FINEP 01/2001/12 - Fundo Verde-Amarelo. Salvador, UFBA/ FAPEX. Programa de desenvolvimento e gestão social: uma construção coletiva. In: FISCHER, T. M. D.; ROESCH, S.; MELO, V. P. Gestão do desenvolvimento territorial e residência social: casos para ensino. Salvador: EDUFBA, CIAGS/UFBA, 2006. p.13-41.

FRANÇA-FILHO, G. C.; LAVILLE, J. L. Economia

Solidária: uma abordagem internacional. Porto Alegre: EDUFRGS, 2004.

FRANÇA-FILHO, G. C. et al. (Org.). Ação pública e economia solidária: uma perspectiva internacional. EDUFRGS-EDUFBA, Porto Alegre-Salvador, 2006.

FRANÇA-FILHO, G. C. Definindo gestão social. In: SILVA, J. T. JR. et al. Gestão Social. Práticas em debate, teorias em construção. Juazeiro do Norte, CE: Liegs/UFC, 2008. p. 26-37.

GASKELL, G. Pesquisa qualitativa com texto, imagem e som. Petrópolis: Vozes, 2002.

\section{GOHN, M. G. História dos movimentos e lutas}

sociais: a construção da cidadania pelos brasileiros. São Paulo: Loyola, 1995.

GONDIM, S.; FISCHER, T.; MELO, V. P. Formação em gestão social: um olhar crítico sobre uma experiência de pós-graduação. In: FISCHER, T.; ROESCH, S.; MELO, V. P. (Org.). Gestão do desenvolvimento territorial e residência social: casos para ensino. Salvador: EDUFBA, CIAGS/UFBA, 2006. p. 43-61. 
JUNQUEIRA, L. A. P. Gestão social: organização, parceria e redes sociais. In: CANÇADO, A. C. et al. Os desafios da formação em Gestão Social. Palmas, TO: Provisão, 2008. p. 87-103.

MAIA, M. Práxis da gestão social nas organizações sociais - uma mediação para a cidadania. 2005. 286 p. Tese (Doutorado em Serviço Social) - Pontifícia Universidade Católica do Rio Grande do Sul. Porto Alegre: PUC-RS, 2005.

MARIOTTI, H. As paixões do ego: complexidade, política e solidariedade. São Paulo: Palas Athena, 2000.

\section{MARTELETO, R. M.; RIBEIRO, L. B. Informações e} Construção do Conhecimento para a Cidadania no Terceiro Setor: Projeto Integrado de Pesquisa, Cultura, Informação e Sociedade; estudo das práticas de informação em campos sociais específicos com vistas à revisão e ampliação de modelos de comunicação e transferência da informação. Universidade Federal do Rio de Janeiro (UFRJ). Rio de Janeiro: Financiamento CNPQ, 1997.

MENDONÇA, P. M.; GONÇALVES-DIAS, S. L. F.; JUNQUEIRA, L. A. P. Gestão Social: notícias sobre o campo de estudos e práticas a partir das interações e debates do VI Enapegs. Revista Administração Pública, Rio de Janeiro, v. 46, n. 5, p. 1.391-1.408, set.out. 2012.

PINHO, J. A. G. (Coord.) Desenvolvimento territorial, organizações e gestão. MBA em Desenvolvimento Regional Sustentável. Brasília, DF: Universidade Corporativa Banco do Brasil, 2006. p. 25-47.

\section{SACHS, I.; LOPES, C.; DOWBOR, L. Crises e}

oportunidades em tempo de mudança. Bahia: Fórum Social Mundial da Bahia, janeiro de 2010.

SCHOMMER, P. C.; BOULLOSA, R. F. Com quantas andorinhas se faz um verão? Práticas, relações e fronteiras de aprendizagem. In: SCHOMMER, P. C.; SANTOS, I. G. Aprender se aprende aprendendo: construção de saberes na relação entre universidade e sociedade. Salvador: CIAGS/UFBA, FAPESB; SECTI; CNPQ, 2010. p. 18-41.
SCHOMMER, P. C.; FRANÇA-FILHO, G. C. Gestão Social e aprendizagem em comunidades de práticas: interações conceituais e possíveis decorrências em processo de formação. In: SILVA JR., J. T. Gestão Social: práticas em debates, teorias em construção. Laboratório Interdisciplinar de Estudos em Gestão Social. Juazeiro do Norte: Universidade Federal do Ceará, julho de 2008. p. 58-83.

SCHOMMER, P. C.; FRANÇA-FILHO, G. C. (2006). A metodologia da residência social e a aprendizagem em comunidades de prática. In: FISCHER, T.; ROESCH, S.; MELO, V. P. (Org.). Gestão do desenvolvimento territorial e residência social: casos para ensino. Salvador: EDUFBA, CIAGS/UFBA, 2006, p. 63-82.

SINGER, P. A Cooperativa é uma empresa socialista. In: GUIMARÃES, G. (Org.). Sindicalismo e

Cooperativismo: a economia solidária em debate, transformações no mundo do trabalho. São Paulo: UNITRABALHO, 2000. p. 79-91.

SALAMON, L.; ANHEIER, H. In search of the nonprofit sector I: the question of definitions. Voluntas, [S.I.], v. 3, n. 2, 1992.

TENÓRIO, F. G. Superando a ingenuidade: minha dívida a Guerreiro Ramos. Revista de Administração Pública, [S.l.], v. 31, n. 5, p. 29-44, set.-out. 1997.

TENÓRIO, F. G. Flexibilização organizacional: mito ou realidade? Rio de Janeiro: Fundação Getúlio Vargas, 2000.

TENÓRIO, F. G. Um espectro ronda o terceiro setor, o espectro do mercado: ensaios sobre a gestão social. 2 . ed. Ijuí: Unijuí, 2004.

TENÓRIO, F. G. (Re)Visitando o Conceito de Gestão Social. In: LIANZA, S.; ADDOR, F. (Org.) Tecnologia e desenvolvimento social e solidário. Porto Alegre: Editora da UFRGS, 2005. p. 101-124.

TENÓRIO, F. G. A trajetória do Programa de Estudos em Gestão Social (PEGS). Revista de Administração Pública, [S.1], v. 40, n. 6, dez. 2006.

TENÓRIO, F. G. Um espectro ronda o terceiro setor: o espectro do mercado. Revista de Administração Pública, [S.l.], v. 33, n. 5, p. 85-102, 1999. 
Júnia Guerra • Armindo dos Santos de Sousa Teodósio

TEODÓSIO. A. S. S. Parcerias tri-setoriais em políticas públicas: desafios para o entendimento de seus desdobramentos na esfera pública. In: RIGO, A. S. (Org.). Gestão Social e Políticas Públicas de Desenvolvimento: ações, articulações e agenda. Juazeiro/Petrolina: UNIVASF. 2010. p. 135-167.

YIN, R. K. Estudo de Caso: planejamento e métodos. 3. ed. Porto Alegre: Bookman, 2007. 